A proxi mal di rect repeat mot if char acterized as a negat i ve regul at or $y$ el ement i $n$ the human reni $n$ gene

\begin{tabular}{|l|l|}
\hline 著者 & $\begin{array}{l}\text { KONOSH TA Tadashi, FUCHS Sebast i en, MAK NO } \\
\text { Yasukazu, WAKAHARA Shi geyuki, M YAMORI I sami }\end{array}$ \\
\hline $\begin{array}{l}\text { j our nal or } \\
\text { publ i cat i on ti t l e }\end{array}$ & Journal of cel I ul ar bi ochemi st ry \\
\hline vol une & 102 \\
\hline number & 4 \\
\hline page r ange & 1043 1050 \\
\hline year & $2007-11$ \\
\hline URL & ht t p: //hdl . handl e. net /10098/1816 \\
\hline
\end{tabular}




\section{Journal of Cellular Biochemistry}

WILEY

A Proximal Direct Repeat Motif Characterized as a Negative Regulatory Element in the Human Renin Gene

\begin{tabular}{|r|l|}
\hline Journal: & Journal of Cellular Biochemistry \\
\hline Manuscript ID: & JCB-06-0667 \\
\hline Datey - Manuscript type: & Research Article \\
\hline Author: & 12 -Oct-2006 \\
\hline & $\begin{array}{l}\text { Complete List of Authors: } \\
\text { Kakino, Yasukazu; Fukui University School of Medicine, Third } \\
\text { Department } \\
\text { Wakahara, Shigeyuki; Fukui University School of Medicine, Third } \\
\text { Department of Internal Medicine } \\
\text { Miyamori, Isamu; Fukui University School of Medicine, Third } \\
\text { Department of Internal Medicine }\end{array}$ \\
\hline \hline Keywords: & renin, renin-angiotensin system, COUP-TFII, cis-element \\
\hline
\end{tabular}

\section{- ScholaronE" \\ Manuscript Central}


A Proximal Direct Repeat Motif Characterized as a Negative Regulatory Element in the Human Renin Gene

Short title: A Negative Regulatory Element in the Human Renin Gene

Tadashi Konoshita MD, $\mathrm{PhD}^{\mathrm{a}}$, Sébastien Fuchs $\mathrm{MD}, \mathrm{PhD}^{\mathrm{b}}$, Yasukazu Makino MD ${ }^{\mathrm{a}}$, Shigeyuki Wakahara $\mathrm{MD}^{\mathrm{a}}$, Isamu Miyamori $\mathrm{MD}, \mathrm{PhD}^{\mathrm{a}}$

${ }^{\mathrm{a}}$ Third Department of Internal Medicine, Fukui University School of Medicine, 23-3, Shimoaizuki, Matsuoka, 910-1193, Japan

${ }^{\mathrm{b}}$ Department of Pathology, Emory University, Atlanta, Georgia 30322

Conflict of interest: NONE

Correspondence: Tadashi Konoshita; Third Department of Internal Medicine, Fukui University School of Medicine, 23-3, Matsuokashimoaizuki, Eiheiji, 910-1193, Japan; Tel: 81-776-61-8353; Fax 81 -776-61-8111; E-mail: konosita@fmsrsa.fukui-med.ac.jp 


\begin{abstract}
:
The regulation of renin gene expression is thought to be fundamental to regulation of the total renin-angiotensin system. The human renin gene contains a direct repeat (DR) motif AGGGGTCAC-AGGGCCA in the proximal region (-259/-245 bp), which contains nuclear receptor superfamily binding core motif, AGGTCA, and is the most similar to COUP-TFII consensus. The DR motif was evaluated as a functional ciselement with renal cortex and chorio-decidual cells by footprint assay, electromobility shift assay (EMSA) and reporter assay. The DR motif site was protected by footprint analysis with a clear hypersensitive and a minor hypersensitive region in good accordance with the DR of the consensus. One of the binding proteins was strongly suspected to be COUP-TFII-consensus-specific by EMSA. The DNA/protein complexes obtained with nuclear extract of renin producing cells could be completely blocked by homologous competitor and strongly blocked by the second-half mutant oligonucleotide of the DR motif but not by the first-half mutant oligonucleotide. Finally, the transcriptional activity of second-half mutant construct is slightly elevated and that firsthalf mutant construct is significantly stronger by 2-fold compared with wild type construct in reporter assay. These findings suggest that the DR motif site of the human renin gene functions as a negative regulatory element involved in a 2-fold repression of transcription and that member (s) of nucleic receptor superfamily bind the site and play important roles in the human renin gene expression with a possibility that one of the binding protein is COUP-TFII.
\end{abstract}

Key words: renin, renin-angiotensin system, COUP-TFII, trans-factor, cis-element 


\section{Introduction}

The renin-angiotensin system (RAS) plays major roles in blood pressure regulation and electrolyte metabolism [Corvol et al. 1997]. The rate-limiting step of the system is the conversion of angiotensinogen to angiotensin I catalyzed by renin. Thus, the regulation of renin gene expression is thought to be fundamental to the regulation of the total system. Several human cell types have been used as models for renin-producing cells, one being human chorio-decidual cells [Pinet et al. 1988], as no human juxtaglomerular (JG) cell line currently exists, although a mouse line, As4.1, has been produced by transformation of JG cells with SV40 large T antigen [Sigmund et al. 1990]. Germain et al. showed that a 250-bp region located about $6 \mathrm{~kb}$ upstream from the transcription starting point of the human renin gene gave up to 57-fold higher transcription rates and is a distal enhancer with human chorio-decidual cells [Germain et al. 1998]. On the other hand, Fuchs et al. recently identified a negative calcium response element (nCaRE) about $1.7 \mathrm{~Kb}$ upstream [Fuchs et al. 2003]. They also showed that $12 \mathrm{~kb}$ of 5 ' region of the human renin gene are needed for tissue-specific and regulated the human renin gene expression in transgenic mice [Fuchs et al. 2002]. These data indicate the importance of the distal enhancers for tissue-specific and regulated the human renin gene expression. Nevertheless, it is well known that proximal promoter regions of gene are indispensable for the regulation of the basic portion of gene expression. Recently, proximal promoters of mouse renin gene have been well investigated [Pan et al. 2001, Petrovic et al. 1996], whereas the human proximal promoter remains to be elucidated. Previously, we mapped 6 protein-binding sites in the proximal promoter region of the human renin gene (-336 to +16) by DNase I footprint assay with nuclear extract from human chorio-decidual cells or ischemic human renal cortex and designated these candidate cis-elements as footprint 
A to F temporarily [Borenszteinet al. 1994, Germain et al. 1996, Konoshita et al. 1996]. Human renal cortex does not consist of homogeneous cells, but, at least, the presence of nuclear factors binding to the human renin promoter has been proven with this method. Searching for similar sequences with the footprint $\mathrm{A}$ to $\mathrm{F}$ among known consensus as cis-elements, we have hypothesized putative cis-elements: Ets motif like site (A: -29/-6) [Wasylyk et al. 1993], CRE (D: -234/-214) [Montminy et al. 1986], COUP-TFII (ARP1) motif like direct repeat site (E: -259/-245) [Ladias et al. 1991]. The candidate human renin CRE was proven to be a genuine CRE [Borensztein et al., 1994, Smith et al. 1994]. Initially, footprint B (-79/-62) was regarded as containing Pit-1 motif like sequence [Borensztein et al., 1994]. We demonstrated that the CRE and footprint B are implicated in the regulation of the human renin gene transcription by cAMP, but, at the same time demonstrated that the protein from chorionic-decidual cell binding to this region is distinct from Pit-1 [Germain et al., 1996]. A recent report indicates that this corresponding region of mouse $\operatorname{Ren}-I^{c}$ is $\mathrm{HOX}-\mathrm{PBX}$ recognition sequence although whether HOX and PBX proteins bind to the human proximal promoter element has not been examined [Pan et al., 2001]. Footprint C (-116 to -80$)$ contains no known consensus sequence. Footprint F (F: -293/-272) contains an AGE3 like site but the corresponding factor has not been identified [Tamura et al. 1994]. Of these 6 genuine or putative cis-elements of the human renin gene, we compared the DNA/nuclear protein binding patterns between renin-producing cells and non-renin-producing cells by electromobility shift assays (EMSA) and showed that the Footprint E, a direct repeat motif site has a obvious heterogeneity, suggesting that the site is involved in cell type specific renin production [Konoshita et al. 2004].

The aim of the present study was to characterize the direct repeat motif site 
(AGGGGTCAC-AGGGCCA, -259/-245 bp), which contains steroid receptor superfamily binding core motif, AGGTCA [Giguere 1999] and is the most similar to the COUP-TFII consensus, as a functional cis-element of the human renin gene.

\author{
Materials and Methods
}

Preparation of COUP-TFII (ARP-1) containing cellular extract from COS-1 cells, nuclear extract from human renal cortex and chorio-decidual cells. COUP-TFII (ARP1) containing cellular extracts and nuclear extracts from human renal cortex and human chorio-decidual cells were prepared as described previously [Konoshita et al., 2004].

DNase I footprint analysis. DNase I footprint analysis was performed as described previously [Konoshita et al., 1996]. Briefly; the -336 to +16 fragment of the renin gene was inserted in Bluescript. Primers were labeled with $\left[\gamma-{ }^{32} \mathrm{P}\right] \mathrm{ATP}$ and T4 polynucleotide kinase before PCR amplification. Footprint analysis was performed in a $10 \mu \mathrm{l}$ reaction mixture. After 20 minutes of incubation at $4{ }^{\circ} \mathrm{C}, 2 \mu \mathrm{l}$ of DNase I (Boehringer Mannheim, $10 \mathrm{IU} / \mu \mathrm{l}$ ) was added, and digestion was allowed to proceed for 1 minute at $20{ }^{\circ} \mathrm{C}$. The reaction mixture was incubated for 45 minutes at $42{ }^{\circ} \mathrm{C}$ with stop solution for DNAse inactivation.

Electromobility shift assays (EMSA). Table 1 summarizes the sequences of oligonucleotides used for EMSA. EMSA was performed as described previously [Konoshita et al., 2004]. Briefly, double-stranded oligonucleotides were synthesized (Applied Biosystems) and end-labeled with $\left(\gamma-{ }^{32} \mathrm{P}\right)$ ATP and T4 polynucleotide kinase. Binding reactions for COUP-TFII-REN, ere performed incubating COUP-TFII (ARP1) transfected Cos-1 extract or each nuclear extract. These were incubated with labeled oligonucleotides with or without competitor oligonucleotides COUP-TFII-M1 mutated 
at the latter half of the consensus and COUP-TFII-M2 mutated at the first half of the consensus. (Table 1). To well characterize the direct repeat, the 2 oligonucleotides were newly designed completely different from those of our previous study [Konoshita et al., 2004].

Plasmid constructions and site-directed mutagenesis. The plasmid $\mathrm{pGL}_{2} 582+$ was constructed as described previously [Germain et al., 1996]. The resulting plasmid $\mathrm{pGL}_{2} 582+$ contained nucleotides $(-582 /+16)$ of the renin gene followed by the luciferase coding sequence. For site-directed mutagenesis, the HidIII fragment (-582/+16) was inserted into the polylinker of the M13mp18 vector (Boehringer Mannheim) to produce single-stranded DNA. COUP-TFII-M1 oligonucleotide replaced the latter half of the consensus, AGGG by GGTA (-249/-246) and COUP-TFII-M2 replaced the first half of the consensus GGTCA by AGATC (-255/-251). In vitro mutagenesis was performed with a Muta-Gene D kit (Bio-Rad), and the mutated sequences were confirmed by sequencing on both strands. The mutated fragments were then subcloned into $\mathrm{pGL}_{2}$ basic creating plasmid $\mathrm{pGL}_{2} 582 \mathrm{COUP}-\mathrm{TFII}-\mathrm{M} 1$ in which the latter half of COUP-TFII consensus was mutated, and $\mathrm{pGL}_{2} 582 \mathrm{COUP}-\mathrm{TFII-M} 2$ in which the first half of COUPTFII consensus was mutated (Fig. 1). All constructions were verified by the dideoxy sequencing method (Sequenase Version 2.0 DNA Sequencing Kit, USB).

Cell culture and transfections and reporter assays. Primary and secondary cultures of human chorio-decidual cells were prepared as described previously [Pinet et al., 1988]. Transient DNA transfections of chorio-decidual cells were performed by calcium phosphate precipitation as described previously [Borensztein et al., 1994]. Transfected cells were washed three times with PBS, lysed by adding $150 \mu \mathrm{l}$ of $1 \%$ Triton, $10 \mathrm{mM}$ $\mathrm{MgCl}_{2}, 1 \mathrm{mM}$ EDTA, $25 \mathrm{mM}$ Tris/phosphate, $\mathrm{pH} 7.8,15 \%$ (w/v) glycerol, $1 \mathrm{mM}$ 
dithiothreitol and $0.2 \mathrm{mM}$ PMSF, and harvested by scraping. The lysates were centrifuged and the supernatant used immediately for the luciferase assay. Luciferase activity was estimated by measuring luminescence for $10 \mathrm{~s}$ with a Bio.Orbit 1250 luminometer, $30 \mathrm{~s}$ after addition of $50 \mu \mathrm{l}$ of luciferase reporter buffer (Promega). Quantitative determination of chloramphenicol acetyltransferase (CAT) was performed by a sandwich immunoassay (Boehringer Mannheim).

Results

Demonstration of the sequence-specific binding of nuclear protein(s) from human renal cortex to the direct repeat motif site of the human renin gene promoter (-259/-245) by DNase I footprint analysis and EMSA. To characterize the direct repeat motif site of the human renin gene promoter, which was designated as footprint E previously [Borensztein et al., 1994], a DNase I footprint analysis was performed with human renal cortex nuclear extracts. The direct repeat site (-259/-245) is protected by renal protein (s) (Figure 2). As shown at the left side of the figure with nucleotides sequence, the protected region is in good accordance with the nuclear receptor family binding consensus (AGGTCA) [Giguere 1999], especially with COUP-TFII consensus sequence (AGGGGTCAN-AGGGNTCA). The protected region showed a clear hypersensitive region and a minor hypersensitive region inside, which are also in good accordance with the direct repeat of the consensus, strongly indicating the binding of proteins in a sequence-specific manner of the nuclear receptor family.

To more thoroughly characterize the sequence-specific binding of human renal cortex nuclear extracts to the direct repeat motif site of the human renin gene, electromobility shift assays (EMSA) were performed with COUP-TFII transfected Cos-1 
cell extracts (COUP TFII protein) and human renal cortex nuclear extracts with a labeled oligonucleotide (-269/-233) corresponding to the site of the human renin gene (COUP-TFII-REN). Especially, to best characterize the direct repetitive sequence of the consensus, besides the homologous competitor (COUP-TFII-REN, we synthesized 2 types of mutant competitors a second-half mutant oligonucleotide (COUP-TFII-M1) and a first-half mutant oligonucleotide (COUP-TFII-M2). These 2 oligonucleotides were newly designed completely different from those of our previous study [Konoshita et al., 2004] to well characterize the direct repeat. As shown in the left panel of Figure 3, with COUP-TFII protein, one specific high-affinity DNA/protein complex was formed with the COUP-TFII consensus like site of the human renin gene. The complex could be completely blocked by homologous competitor (COUP-TFII-REN and strongly blocked by the second-half mutant oligonucleotide (COUP-TFII-M1) but not by the first-half mutant oligonucleotide (COUP-TFII-M2). With renal cortex nuclear extracts among non-specific complexes, consensus-specific DNA/protein complex showing the same migration and competition manner as COUP-TFII protein was observed, suggesting that the nuclear protein from renal cortex is COUP-TFII itself or other members of the nuclear receptor superfamily. Such DNA/protein complex was not observed with the nuclear extracts from non-renin producing JGE3 cells or HepG2 cells [Konoshita et al., 2004]. Before proceeding to functional evaluation of the consensus site, we had to characterize the nuclear extracts of model culture cells. As human chorio-decidual cells are well known as a good model for human renin-producing cells, EMSA was performed with the nuclear extracts of these cells. As shown in the right panel of Figure 3, with nuclear extracts from chorio-decidual cells, consensus-specific DNA/protein complex showing the same migration and competition manner as COUP-TFII protein and renal 
cortex nuclear extracts was observed, suggesting that the nuclear protein from renal cortex is COUP-TFII itself or other members of the nuclear receptor superfamily.

Demonstration of the direct repeat motif site in the human renin gene promoter as a negative regulatory element.

To characterize functionally the direct repeat motif site of the human renin gene which was demonstrated as a sequence-specific nuclear protein binding site, a series of chimeric genes was constructed in which the consensus site of the gene was mutated and fused to a luciferase reporter gene (Figure 1). Two types of mutant were introduced to the site, of which each direct repeat consensus (AGGGGTCAN-AGGGNTCA) was replaced by non-specific nucleotides that were the same as the oligonucleotides designed for EMSA (Fig. 2). The latter half of the consensus AGGG (-249/-246) of by GGTA of pGL ${ }_{2} 582+$ was mutated to GGTA creating pGL $_{2} 582+$ COUP-TFII-M1, whereas the first half of the consensus GGTCA (-255/-251) was mutated to AGATC creating $\mathrm{pGL}_{2} 582+\mathrm{COUP}-\mathrm{TFII}-\mathrm{M} 2$. These constructs were then transfected into human choriodecidual cells which express the renin gene. Transfection efficiency was controlled by co-transfection with the pRSV-CAT plasmid. The results show that the promoter activity of $\mathrm{pGL}_{2} 582+\mathrm{COUP}-\mathrm{TFII}-\mathrm{M} 1$ is slightly elevated and that $\mathrm{pGL}_{2} 582+\mathrm{COUP}-\mathrm{TFII}-\mathrm{M} 2$ is significantly stronger compared with $\mathrm{pGL}_{2} 582+$ (Fig. 4). The transcription activities of $\mathrm{pGL}_{2} 582+$, pGL $2582+\mathrm{COUP}-\mathrm{TFII}-\mathrm{M} 1$ and $\mathrm{pGL}_{2} 582+\mathrm{COUP}-\mathrm{TFII}-\mathrm{M} 2$ were $100 \pm 14 \%$, $110 \pm 24 \%$ and $203 \pm 41 \%$, respectively. These results suggest that the direct repeat motif site of the human renin gene functions as a negative regulatory element involved in an about 2-fold repression of transcription. Furthermore, the activities are in good accordance with the results obtained by EMSA. These results confirm that the sequence- 
specific binding has an important significance and indicated that the first half of the direct repeat is essential for the negative regulatory function.

\section{Discussion}

The main findings of the previous and present studies as summarized below strongly indicate that the direct repeat motif in the human renin gene is a negative regulatory element involved in an about 2-fold suppression in transcription: (a) The site is consensus specific with renin producing cell nuclear extracts [Konoshita et al., 1996, Konoshita et al., 2004]; (b) The site showed the protected region with 2 hypersensitive regions in good accordance with the direct repeat of the consensus by DNase I footprint analysis; (c) The DNA/protein complexes by EMSA is completely blocked by homologous competitor and strongly blocked by the second-half mutant oligonucleotide of the direct repeat motif but not by the first-half mutant oligonucleotide with renal cortex nuclear extract and chorio-decidual cell nuclear extract; (d) Deletion of the site showed an augmentation of transcript activity in a 5' -deletion mutant reporter assay by about 1.5-fold [Borensztein et al., 1994]; and (e) Reporter assay showed that the mutation of the first portion of the binding region results in a significant increase of the transcriptional activity of the proximal promoter by 2 -fold whereas the mutation of the second portion has only minimal effects. These observations are in good accordance with the results of the binding assay. Taken together, our results suggest that it is the first half of the direct repeat that is essential for the protein binding and the negative regulatory function. 
In the present study, the nuclear protein binding to the direct repeat of the human renin gene in a sequence-specific manner might be COUP-TFII itself Chicken ovalbumin upstream promoter-transcription factors (COUP-TFs) are orphan members of the steroid/thyroid hormone receptor superfamily [Pereira et al. 2000]. COUP-TFI was discovered as a transcription factor that bound a specific element, which regulates transcription of the ovalbumin gene [Wang et al. 1989]. Apolipoprptein regulating protein 1 (ARP-1) was cloned as a repressor for the apolipoprotein AI [Ladias et al., 1991] and was proven to be identical with COUP-TFII, a homologue of COUP-TFI [Wang et al. 1991]. COUP-TFs are fundamentally regarded as negative regulators for a large number of genes, whereas they can also activate a growing number of gene promoters [Pereira et al., 2000]. COUP-TFs are thought to exist as homodimers and as heterodimers with RXR with consensus motifs essentially composed of AGGTCA core direct repeats. Consensus for ARP-1 (COUP-TFII) was first identified and characterized as AGGGGTCAN-AGGGNTCA (TGANCCCT-NTGACCCCT) [Ladias et al., 1991]. The human renin gene AGGGGTCAC-AGGGCCA (-259/-245) possesses a strong similarity with this motif. COUP-TFII is expressed in the salivary gland, atrium of the heart, mesonephros and kidney [Pereira et al. 1995]. Some important roles are suggested in the regulation of steroidogenesis in human adrenal cortex and its disorders [Shibata et al. 2001, Suzuki et al. 2000]. COUP-TFII null mutant mice die in utero due to defects in angiogenesis, vascular remodeling and heart development, indicating the important role for this sequence in the correct development of the vascular system [Pereira et al. 1999]. Considering these characteristics of COUP-TFII, the sequence-specific repression of the human renin gene via the COUP-TFII motif like site might play important roles in cardiovascular-renal development and regulation. 
The murine Ren- $I^{d}$ homologous promoter site of the human COUP-TFII motif site (259/-245) is thought to be located at about $-700 \mathrm{bp}$ from the transcription starting point [Burt et al. 1989]. The sequence of the corresponding site is AGAGGTTGCGGGCCCA and is considerably different from the human sequence AGGGGTCACAGGGCCA, especially with respect to the fact that no AGGTCA core direct repeat is found, so that the corresponding site does not seem to function as a cis-element for COUP-TFII. On the other hand, recent reports revealed the pivotal functions of nuclear transcription factors on murine renin gene promoter, consisting of LXR $\alpha$ [Tamura et al. 2000], retinoic acid [Shi et al. 2001], vitamin D3 [Li et al. 2002] and Ear2 [Liu et al. 2003]. The latter 3 ligands share the common cis-element containing AGGTCA motif at about $-2,000 \mathrm{bp}$. It is possible that the direct repeat motif site $(-259 /-245)$ of the human renin gene that contains AGGTCA repeat is also involved in these other members of nuclear receptor superfamily and that competitive occupation of the site or competitive forming of homo- or hetero-dimers play some roles in the gene expression.

In conclusion, these findings suggest that the direct repeat motif site of the human renin gene functions as a negative regulatory element involved in a 2-fold suppression of transcription and that some corresponding nucleic receptors might play important roles in the human renin gene expression. Further elucidation would be necessary to clarify the role of the DR by the use of other human renin-producing cells, Calu6 cells [Lang et al. 1995], and experiments with a mutated DR element within a longer promoter fragment.

Acknowledgments 
We are grateful to Mr. John S. Gelblum for a critical reading of the manuscript and to Miss Youko Hayashida for secretarialassistance.

\section{References}

Borensztein P, Germain S, Fuchs S, Philippe J, Corvol P, Pinet F 1994. cis-regulatory elements and trans-acting factors directing basal and cAMP-stimulated human renin gene expression in chorionic cells. Circ Res 74:764-773.

Burt DW, Nakamura N, Kelley P, Dzau VJ 1989. Identification of negative and positive regulatory elements in the human renin gene. J Biol Chem 264:7357-7362

Corvol P, Soubrier F, Jeunemaitre X 1997. Molecular genetics of the renin-angiotensinaldosterone system in human hypertension. Pathol Biol (Paris) 45:229-239.

Fuchs S, Germain S, Philippe J, Corvol P, Pinet F 2002. Expression of renin in large arteries outside the kidney revealed by human renin promoter/LacZ transgenic mouse. Am J Pathol 161:717-725.

Fuchs S, Philippe J, Corvol P, Pinet F 2003. Implication of Ref-1 in the repression of renin gene transcription by intracellular calcium. J Hypertens 21:327-335.

Germain S, Bonnet F, Philippe J, Fuchs S, Corvol P, Pinet F 1998. A novel distal enhancer confers chorionic expression on the human renin gene. J Biol Chem 273:25292-25300.

Germain S, Konoshita T, Philippe J, Corvol P, Pinet F 1996. Transcriptional induction of the human renin gene by cyclic AMP requires cyclic AMP response elementbinding protein (CREB) and a factor binding a pituitary-specific trans-acting factor (Pit-1) motif. Biochem J 316:107-113

Giguere V 1999. Orphan nuclear receptors: from gene to function. Endocr Rev 20:689725

Konoshita T, Germain S, Philippe J, Corvol P, Pinet F 1996. Evidence that renal and chorionic tissues contain similar nuclear binding proteins that recognize the human renin promoter. Kidney Int 50:1515-1524.

Konoshita T, Makino Y, Wakahara S, Ido K, Yoshida M, Kawai Y, Miyamori I 2004. Candidate cis-elements for human renin gene expression in the promoter region. J Cell Biochem 93:327-336

Ladias JA, Karathanasis SK 1991. Regulation of the apolipoprotein AI gene by ARP-1, a novel member of the steroid receptor superfamily. Science 251:561-565.

Lang JA, Yang G, Kern JA, Sigmund CD 1995. Endogenous human renin expression and promoter activity in CALU-6, a pulmonary carcinoma cell line. Hypertension 25:704-710

Li YC, Kong J, Wei M, Chen ZF, Liu SQ, Cao LP 2002. 1,25-Dihydroxyvitamin D(3) is a negative endocrine regulator of the renin-angiotensin system. J Clin Invest 110:229-238

Liu X, Huang X, Sigmund CD 2003. Identification of a nuclear orphan receptor (Ear2) as a negative regulator of renin gene transcription. Circ Res 92:1033-1040

Montminy MR, Sevarino KA, Wagner JA, Mandel G, Goodman RH 1986. Identification of a cyclic-AMP-responsive element within the rat somatostatin 
gene. Proc Natl Acad Sci U S A 83:6682-6686.

Pan L, Xie Y, Black TA, Jones CA, Pruitt SC, Gross KW 2001. An Abd-B class HOX.PBX recognition sequence is required for expression from the mouse Ren1c gene. J Biol Chem 276:32489-32494.

Pereira FA, Qiu Y, Tsai MJ, Tsai SY 1995. Chicken ovalbumin upstream promoter transcription factor (COUP-TF): expression during mouse embryogenesis. J Steroid Biochem Mol Biol 53:503-508

Pereira FA, Qiu Y, Zhou G, Tsai MJ, Tsai SY 1999. The orphan nuclear receptor COUP-TFII is required for angiogenesis and heart development. Genes Dev 13:1037-1049.

Pereira FA, Tsai MJ, Tsai SY 2000. COUP-TF orphan nuclear receptors in development and differentiation. Cell Mol Life Sci 57:1388-1398

Petrovic N, Black TA, Fabian JR, Kane C, Jones CA, Loudon JA, Abonia JP, Sigmund CD, Gross KW 1996. Role of proximal promoter elements in regulation of renin gene transcription. J Biol Chem 271:22499-22505.

Pinet F, Corvol MT, Bourguignon J, Corvol P 1988. Isolation and characterization of renin-producing human chorionic cells in culture. J Clin Endocrinol Metab 67:1211-1220.

Shi Q, Gross KW, Sigmund CD 2001. Retinoic acid-mediated activation of the mouse renin enhancer. J Biol Chem 276:3597-3603

Shibata H, Ikeda Y, Mukai T, Morohashi K, Kurihara I, Ando T, Suzuki T, Kobayashi S, Murai M, Saito I, Saruta T 2001. Expression profiles of COUP-TF, DAX-1, and SF-1 in the human adrenal gland and adrenocortical tumors: possible implications in steroidogenesis. Mol Genet Metab 74:206-216.

Sigmund CD, Okuyama K, Ingelfinger J, Jones CA, Mullins JJ, Kane C, Kim U, Wu CZ, Kenny L, Rustum Y, Dzau VJ, Gross KW 1990. Isolation and characterization of renin-expressing cell lines from transgenic mice containing a renin-promoter viral oncogene fusion construct. J Biol Chem 265:19916-19922

Smith DL, Morris BJ, Do YS, Law RE, Shaw KJ, Hseuh WA 1994. Identification of cyclic AMP response element in the human renin gene. Biochem Biophys Res Commun 200:320-329

Suzuki T, Takahashi K, Darnel AD, MoriyaT, Murakami O, Narasaka T, Takeyama J, Sasano H 2000. Chicken ovalbumin upstream promoter transcription factor II in the human adrenal cortex and its disorders. J Clin Endocrinol Metab 85:27522757.

Tamura K, Chen YE, Horiuchi M, Chen Q, Daviet L, Yang Z, Lopez-Ilasaca M, Mu H, Pratt RE, Dzau VJ 2000. LXRalpha functions as a cAMP-responsive transcriptional regulator of gene expression. Proc Natl Acad Sci U S A 97:85138518

Tamura K, Umemura S, Ishii M, Tanimoto K, Murakami K, Fukamizu A 1994. Molecular mechanism of transcriptional activation of angiotensinogen gene by proximal promoter. J Clin Invest 93:1370-1379.

Wang LH, Ing NH, Tsai SY, O'Malley BW, Tsai MJ 1991. The COUP-TFs compose a family of functionally related transcription factors. Gene Expr 1:207-216

Wang LH, Tsai SY, Cook RG, Beattie WG, Tsai MJ, O'Malley BW 1989. COUP transcription factor is a member of the steroid receptor superfamily. Nature 340:163-166 
Wasylyk B, Hahn SL, Giovane A 1993. The Ets family of transcription factors. Eur J Biochem 211:7-18. 
Table 1. Alignment of oligonucleotide sequences used in this study

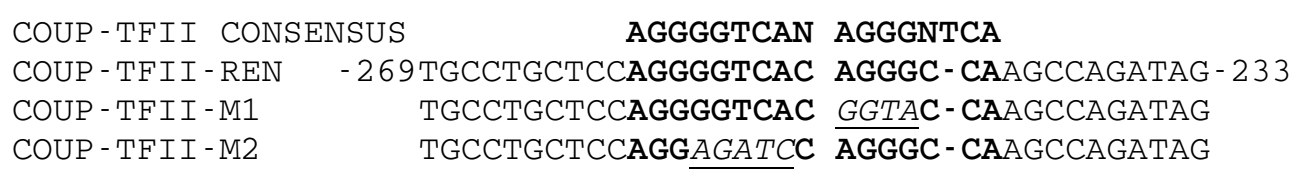

The direct repeat consensus sequence for COUP-TFII is indicated above the oligonucleotides in bold letters. $\mathrm{N}$ represents $\mathrm{G}, \mathrm{A}, \mathrm{T}$ or $\mathrm{C}$. The sequences of all oligonucleotides used for EMSA or as competitors are shown. Top strands only are shown. Underlined and italicized letters in oligonucleotides indicate mutated sequences. 


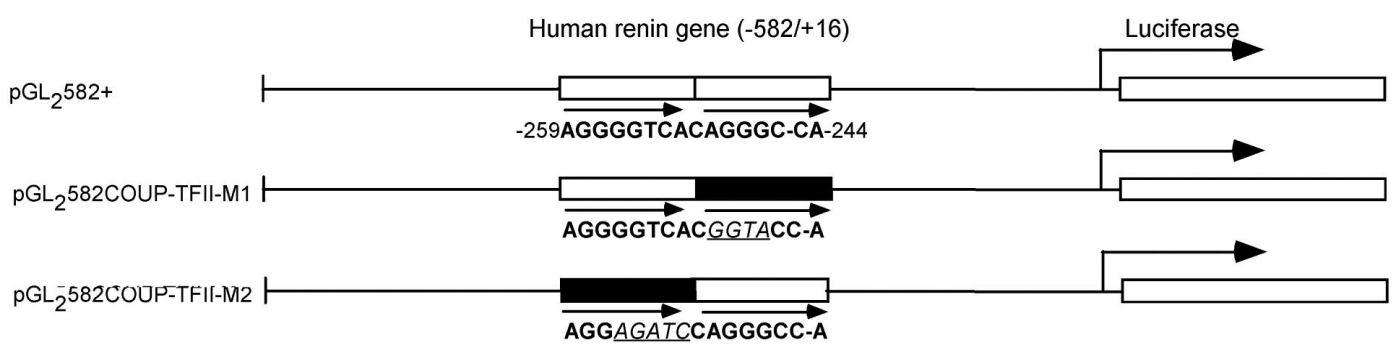

Figure 1. Schematic representation of $\mathrm{pGL}_{2} 582+, \mathrm{pGL}_{2} 582 \mathrm{COUP}-\mathrm{TFII}-\mathrm{M} 1$ and $\mathrm{pGL}_{2} 582 \mathrm{COUP}-\mathrm{TFII}-\mathrm{M} 2$. A $598 \mathrm{bp}$ fragment of the human renin gene $(-582 /+16)$ was isolated by HidIII digestion of phrnCAT06 derived from the plasmid subclone $\lambda \mathrm{HRn} 88$ and subcloned into the HidIII site of pGl ${ }_{2}$ basic. The resulting plasmid pGL $2582+$ contained nucleotides $(-582 /+16)$ of the renin gene followed by the luciferase coding sequence. The HidIII fragment $(-582 /+16)$ was inserted into the polylinker of the M13mp18 vector to produce single-stranded DNA. In vitro mutagenesis was performed with a commercial kit and the mutated sequences were confirmed by sequencing on both strands. The mutated fragments were then subcloned into $\mathrm{pGL}_{2}$ basic creating plasmid pGL ${ }_{2} 582$ COUP-TFII-M1 in which the latter half of COUP-TFII consensus was mutated and $\mathrm{pGL}_{2} 582 \mathrm{COUP}-\mathrm{TFII-M} 2$ in which the first half of COUP-TFII consensus was mutated. Boxes represent repetitive consensus for COUP-TFII. Closed boxes represent the mutated parts of the repetitive consensus sequences. 


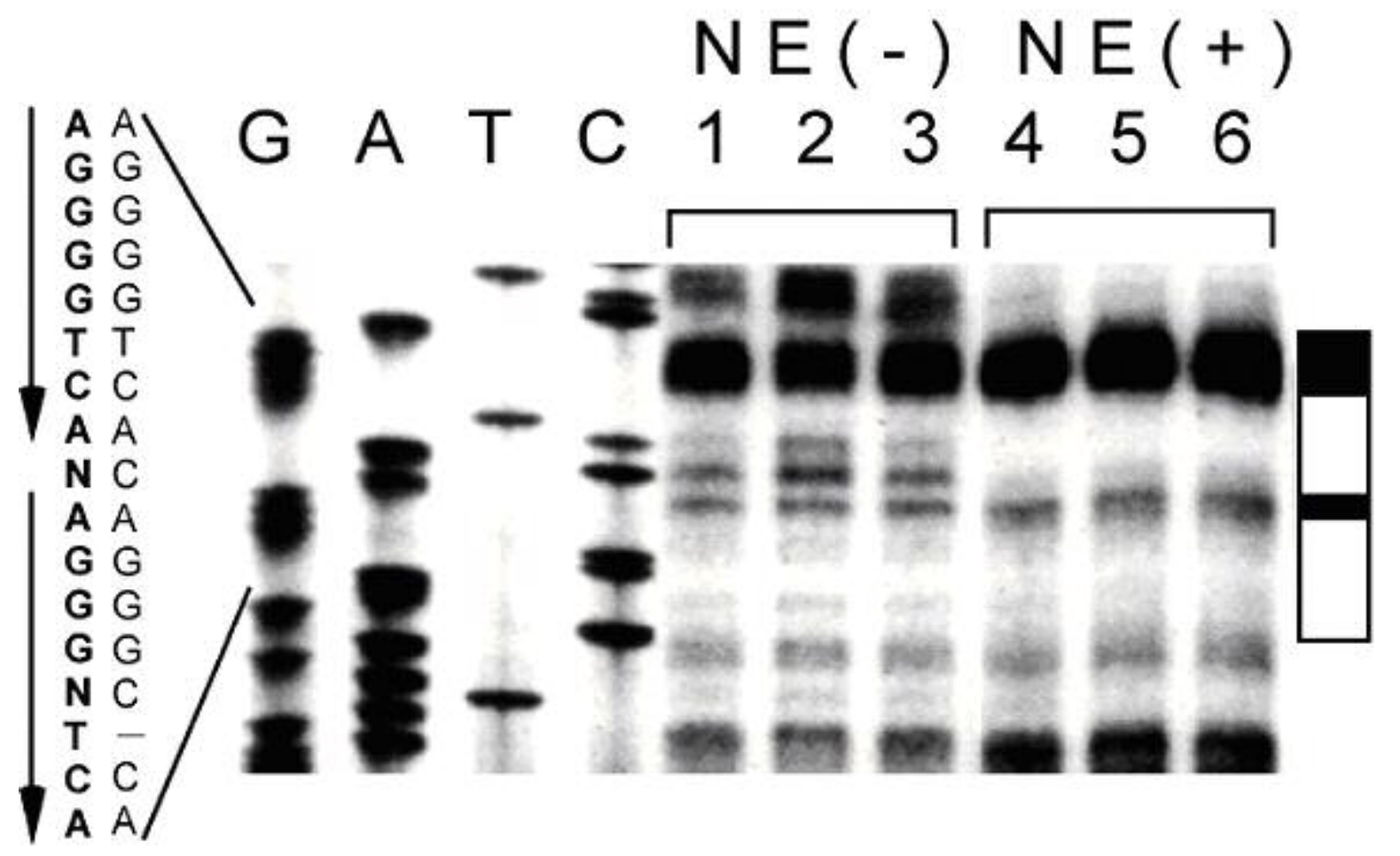

Figure 2. DNase I footprint analysis of the direct repeat motif site of the human renin gene (-259/-245). Footprint analysis was performed with human renal cortex nuclear extracts (NE). G, A, T, C represent the sequencing ladder. Lanes 1 to 3 represent the reaction performed in the absence of nuclear extracts (NE (-)) and decreasing amounts of DNase I (0.1 U, $0.05 \mathrm{U}$ and $0.025 \mathrm{U}$, respectively). Lanes 4 to 6 represent the reaction performed with nuclear extracts $(\mathrm{NE}(+))$ with decreasing amounts of DNase I (0.1 U, $0.05 \mathrm{U}$ and $0.025 \mathrm{U}$, respectively). On the left of the figure, consensus sequences of direct repeat site and of the human renin gene are shown in bold and plain letters, respectively and two vertical arrows beside the consensus sequence represent the direct repeat of the consensus. On the right of the figure, the protected region of the direct repeat motif site and hypersensitive regions are represented as an open and a closed square, respectively. 


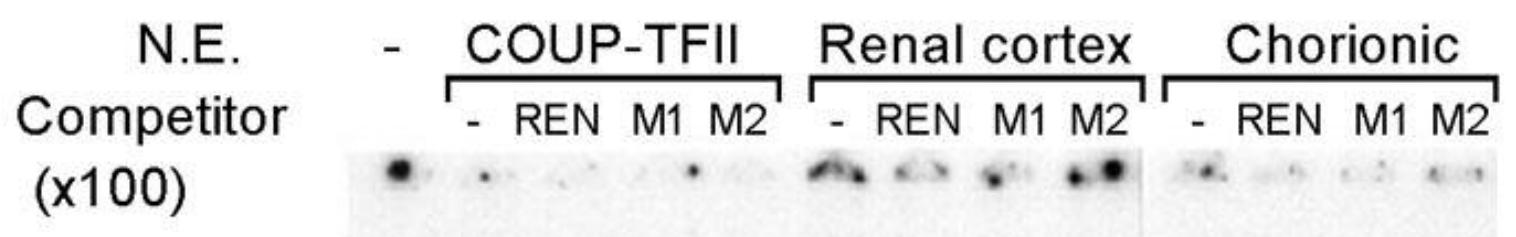

Figure 3. Electromobility shift assay of COUP-TFII transfected Cos-1 extracts and nuclear extracts from renal cortex and chorio-decidual cells $(3 \mu \mathrm{g}$ protein in each reaction) with the direct repeat motif site of the human renin gene promoter (COUPTFII-REN: -269/-233). A double-stranded labeled oligonucleotide containing the direct motif site, COUP-TFII-REN (REN: 269TGCCTGCTCCAGGGGTCACAGGGCCAAGCCAGATAG-233), was used as a probe. Competitions were performed with a 100-fold molar excess of homologous DNA (COUP TFII-REN), mutated oligonucleotide, COUP-TFII-M1 (M1: TGCCTGCTCCAGgGGTCACGGTACCAAGCCAGATAG) or with mutated oligonucleotide COUP-TFII-M2

(M2: TGCCTGCTCCAGGAGATCCAGgGCCAAGCCAGATAG). 2 oligonucleotides were newly designed completely different from those of our previous study [Konoshita et al., 2004] to well characterize the direct repeat. Underlined and 
italicized letters in oligonucleotides indicate mutated sequence. The specific DNA/protein complexes are indicated by the arrow. 


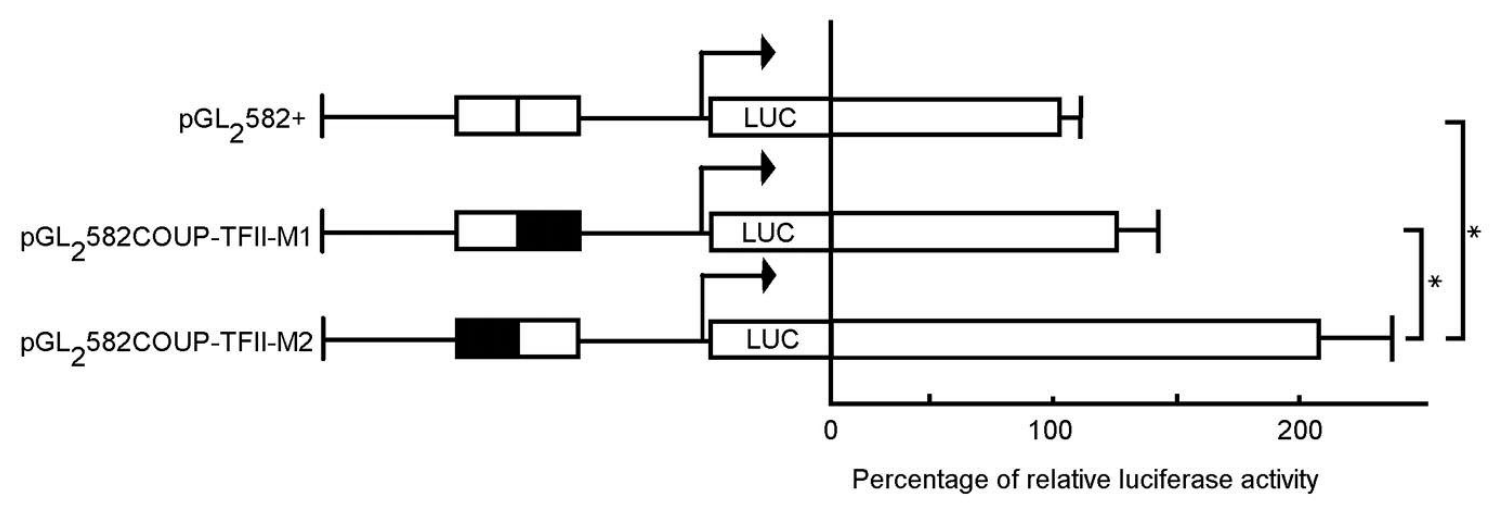

Figure 4. Normalized luciferase activity of different renin promoter/luciferase constructs transfected into chorio-decidual cells. Luciferase activity was normalized to cotransfected RSV-CAT activity and the values were expressed as relative percentage to that of $\mathrm{pGL}_{2} 582$. Each value represents the result of three independent transfection experiments performed in triplicate flasks. Levels of significance were calculated by Student's $t$ test. Groups that are significantly different from each other are indicated by asterisks ( $\mathrm{pGL}_{2} 582$ vs. $\mathrm{pGL}_{2}$ 582COUP-TFII-M1, $\mathrm{p}=0.28$; $\mathrm{pGL}_{2}$ 582COUP-TFII-M1 vs. pGL 2582 COUP-TFII-M2, $\mathrm{p}<0.0001 ; \mathrm{pGL}_{2} 582$ vs. pGL 2582 COUP-TFII-M2, $\left.\mathrm{p}<0.0001\right)$. Boxes represent repetitive consensus. Closed boxes represent the mutated parts of the repetitive consensus sequences. 


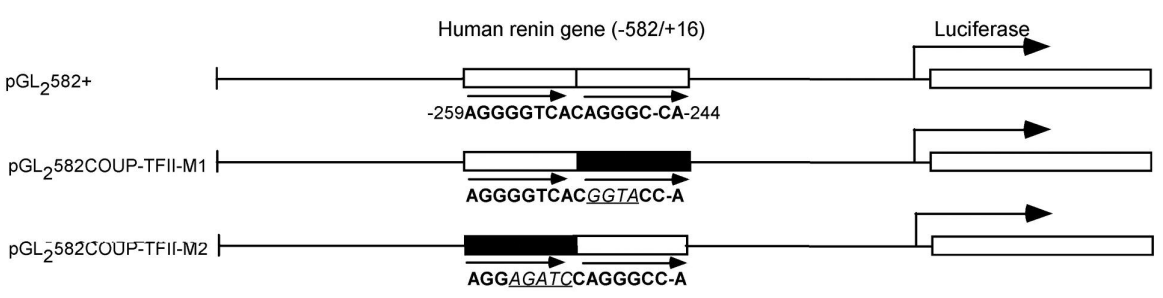

Schematic representation of pGL2582+, pGL2582COUP-TFII-M1 and pGL2582COUP-TFIIM2. A 598 bp fragment of the human renin gene $(-582 /+16)$ was isolated by HindIII digestion of phrnCAT06 derived from the plasmid subclone $\lambda$ HRn 88 and subcloned into the HindIII site of pGI2basic. The resulting plasmid pGL2582+ contained nucleotides ($582 /+16)$ of the renin gene followed by the luciferase coding sequence. The HindIII fragment $(-582 /+16)$ was inserted into the polylinker of the $\mathrm{M} 13 \mathrm{mp} 18$ vector to produce single-stranded DNA. In vitro mutagenesis was performed with a commercial kit and the mutated sequences were confirmed by sequencing on both strands. The mutated fragments were then subcloned into pGL2basic creating plasmid pGL2582COUP-TFII-M1 in which the latter half of COUP-TFII consensus was mutated and pGL2582COUP-TFII-M2 in which the first half of COUP-TFII consensus was mutated. Boxes represent repetitive consensus for COUP-TFII. Closed boxes represent the mutated parts of the repetitive consensus sequences. 


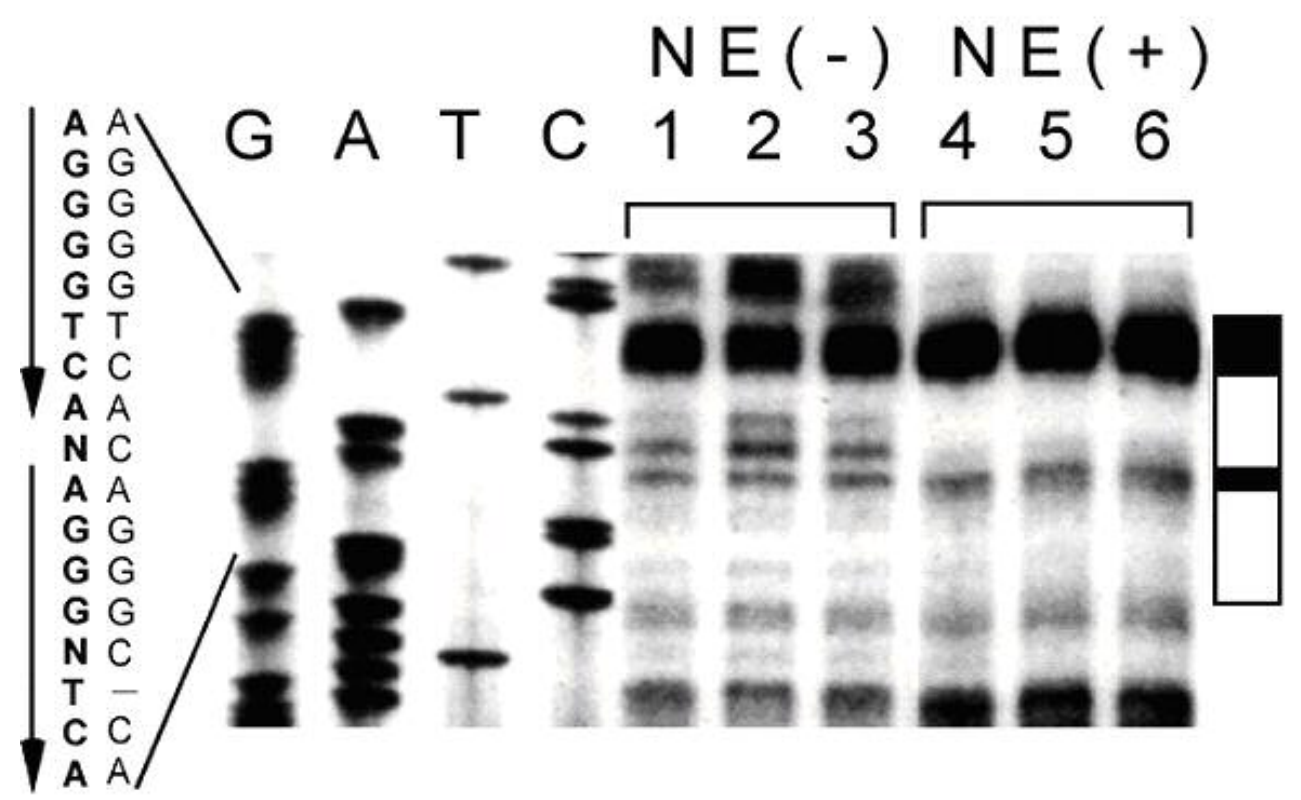

DNase I footprint analysis of the direct repeat motif site of the human renin gene (-259/245). Footprint analysis was performed with human renal cortex nuclear extracts (NE). G, $A, T, C$ represent the sequencing ladder. Lanes 1 to 3 represent the reaction performed in the absence of nuclear extracts (NE (-)) and decreasing amounts of DNase I (0.1 U, 0.05 $U$ and $0.025 U$, respectively). Lanes 4 to 6 represent the reaction performed with nuclear extracts (NE $(+))$ with decreasing amounts of DNase I $(0.1 \mathrm{U}, 0.05 \mathrm{U}$ and $0.025 \mathrm{U}$, respectively). On the left of the figure, consensus sequences of direct repeat site and of the human renin gene are shown in bold and plain letters, respectively and two vertical arrows beside the consensus sequence represent the direct repeat of the consensus. On the right of the figure, the protected region of the direct repeat motif site and hypersensitive regions are represented as an open and a closed square, respectively. 


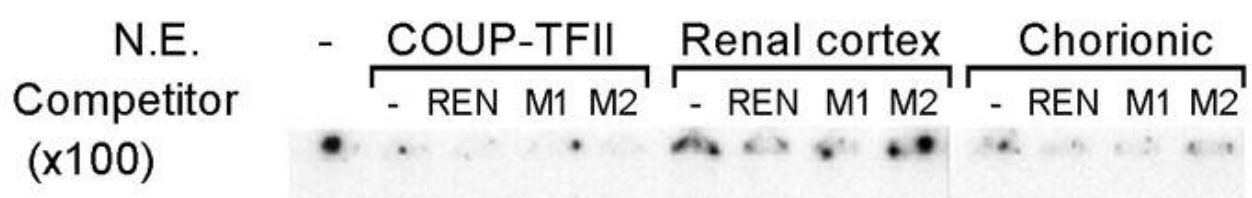

Electromobility shift assay of COUP-TFII transfected Cos-1 extracts and nuclear extracts from renal cortex and chorio-decidual cells ( $3 \mu \mathrm{g}$ protein in each reaction) with the direct repeat motif site of the human renin gene promoter (COUP-TFII-REN: -269/-233). A double-stranded labeled oligonucleotide containing the direct repeat motif site, COUPTFII-REN (REN: -269TGCCTGCTCCAGGGGTCACAGGGCCAAGCCAGATAG-233), was used as a probe. Competitions were performed with a 100-fold molar excess of homologous DNA (COUP-TFII-REN), mutated oligonucleotide, COUP-TFII-M1 (M1:

TGCCTGCTCCAGGGGTCACGGTACCAAGCCAGATAG) or with mutated oligonucleotide COUPTFII-M2 (M2: TGCCTGCTCCAGGAGATCCAGGGCCAAGCCAGATAG). These 2 oligonucleotides were newly designed completely different from those of our previous study [Konoshita et al., 2004] to well characterize the direct repeat. Underlined and italicized letters in oligonucleotides indicate mutated sequence. The specific DNA/protein complexes are indicated by the arrow. 


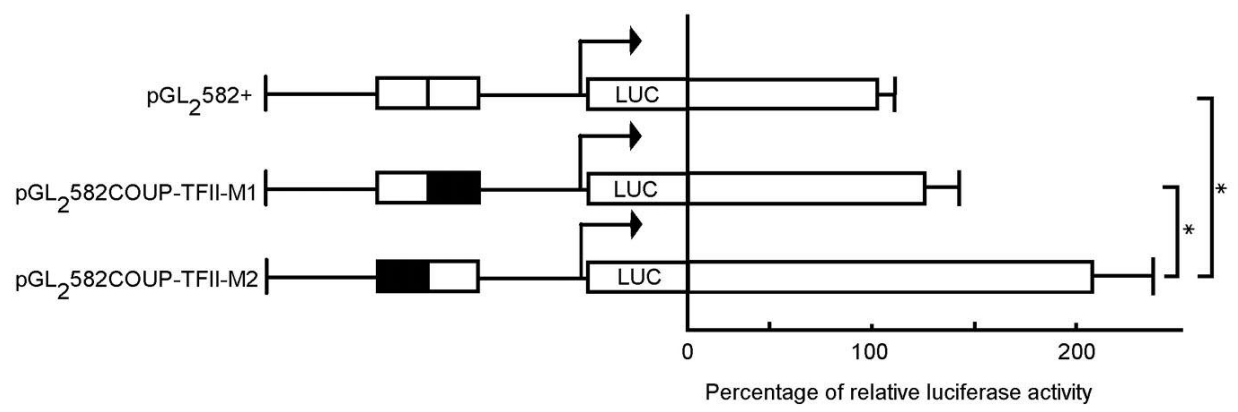

Normalized luciferase activity of different renin promoter/luciferase constructs transfected into chorio-decidual cells. Luciferase activity was normalized to cotransfected RSV-CAT activity and the values were expressed as relative percentage to that of pGL2582. Each value represents the result of three independent transfection experiments performed in triplicate flasks. Levels of significance were calculated by Student's $\mathbf{t}$ test. Groups that are significantly different from each other are indicated by asterisks ( $p$ GL2582 vs. pGL2582COUP-TFII-M1, $p=0.28$; pGL2582COUP-TFII-M1 vs. pGL2582COUP-TFII-M2, p<0.0001; pGL2582 vs. pGL2582COUP-TFII-M2, $p<0.0001$ ). Boxes represent repetitive consensus. Closed boxes represent the mutated parts of the repetitive consensus sequences. 
Table 1. Alignment of oligonucleotide sequences used in this study

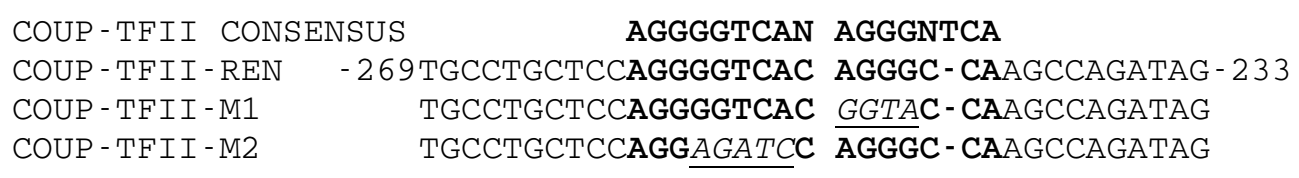

The direct repeat consensus sequence for COUP-TFII is indicated above the oligonucleotides in bold letters. $\mathrm{N}$ represents $\mathrm{G}, \mathrm{A}, \mathrm{T}$ or $\mathrm{C}$. The sequences of all oligonucleotides used for EMSA or as competitors are shown. Top strands only are shown. Underlined and italicized letters in oligonucleotides indicate mutated sequences. 